\title{
Analisis Validitas Pengembangan Bahan Ajar Membaca Dalam Hati Pada Pembelajaran Tematik Terpadu Dengan Strategi OK5R Di Kelas IV Sekolah Dasar
}

\author{
Silviana Nasrul ${ }^{1}$, Ade Irma Suryani ${ }^{2,}$ Sry Apfani ${ }^{3}$ \\ Program Studi PGSD STKIP Adzkia ${ }^{123}$ \\ S.nasrul@stkipadzkia.ac.id ${ }^{1}$, adeirmasuryani278@gmail.com ${ }^{2}$, \\ Apfani.sry@gmail.com ${ }^{3}$
}

\begin{abstract}
Abstrak
Penelitian ini dilatarbelakangi oleh belum tersedianya bahan ajar yang memuat tahapan membaca, yakni prabaca, saatbaca,dan pascabaca dan belum terlihat teknik membaca dalam hati yang benar. Tujuan penelitian ini adalah: (1) menganalisis kebutuhan siswa berkaitan dengan bahan ajar membaca dalam hati. (2) Mengembangkan bahan ajar membaca dalam hati pada pembelajaran tematik terpadu dengan strategi OK5R di Kelas IV SD. (3) Menguji validitas bahan ajar yang dihasilkan. Jenis penelitian ini adalah penelitian pengembangan dengan model pengembangan Plomp yang terdiri dari tiga tahap, yaitu: (1) preliminary research, (2) prototyping phase, dan (3) assesment stage. Pada penelitian ini peneliti meminta bantuan 3 orang validator yaitu validator untuk materi, validator untuk Kebahasaan dan validator untuk design, dari validasi yang dilakukan didapatkan uji validitas $92 \%$ dengan kriteria sangat valid, Berdasarkan hasil tersebut dapat disimpulkan bahwa Pengembangan bahan ajar membaca dalam hati pada pembelajaran tematik terpadu dengan strategi OK5R di Kelas IV Sekolah Dasar telah valid untuk digunakan.
\end{abstract}

Kata Kunci: Bahan Ajar, Membaca Dalam Hati, OK5R, Sekolah Dasar. 


\section{PENDAHULUAN}

Membaca merupakan suatu proses untuk memhami infomrasi apa yang disampaikan noleh penulis. Menurut pendapat Apfani (2018) "Membaca merupakan suatu proses untuk memperoleh informasi dari suatu bentuk tulisan”, juga dipertegas oleh pendapat Taufik (2016) yaitu Membaca merupakan proses interaksi memahami lambang bahasa melalui berbagai strategi untuk memahami makna dari tertulis, melibatkan aktivitas visual, berpikir,psikolinguistik, dan metakognitif. Tahapan kegiatan membaca diantaranya: Tahap prabaca, kegiatan yang dilakukan siswa dapat memprediksi isi bacaan berdasarkan judul dan gambar dari bacaan. Tahap saatbaca, kegiatan yang dilakukan siswa membaca teks bacaan dengan benar. Tahap pascabaca, kegiatan yang dilakukan menjawab pertanyaan dan meringkas bacaan.

Membaca dalam hati harus dilakukan dengan teknik yang benar. Teknik membaca dalam hati yang benar dan diimplementasikan, yaitu: membaca tidak bersuara, bibir tidak bergerak atau komat-kamit, tidak menggerakkan kepala mengikuti baris bacaan, tidak menunjuk baris bacaan dengan jari, pensil, atau lainnya, dan tidak membaca kata demi kata, atau kalimat demi kalimat (Muhammadi, Taufik, dan Chandra, 2018). Pada kurikulum 2013 membaca dalam hati terdapat dalam pembelajaran tematik terpadu karena muatan pelajaran bahasa Indonesia dijadikan sebagai penghela setiap mata pelajaran.

Berdasarkan hasil analisis buku guru dan buku siswa untuk Tema 1, sub tema 1, pembelajaran 1, kelas IV SD dengan KD 3.1 (berdasarkan Permendikbud No. 37 Tahun 2018) masih ada kekurangan diantaranya yaitu (1) bahan ajar yang digunakan belum memunculkan tahap/ proses membaca yang benar, (2) belum memunculkan tujuan membaca yang tepat, (3) belum terlihat teknik membaca dalam hati yang benar. Ditemukanan bahwa proses pembelajaran membaca belum sesuai dengan tahapan prabaca, saatbaca dan pascabaca. Permasalahan yang ditemukan pada bahan ajar pembelajaran membaca yaitu pada kegiatan prabaca siswa kurang diarahkan melakukan prediksi terhadap judul bacaan yang akan dibaca. Dari contoh buku yang digunakan siswa langsung diminta untuk membaca teks bacaan, tanpa melakukan kegiatan memprediksi isi bacaan melalui judul atau gambar yang sesuai dengan isi bacaan. Telah diketahui bahwa melakukan prediksi terhadap judul bacaan merupakan 
langkah awal yang dapat menentukan pemahaman siswa terhadap isi bacaan yang akan dibaca.

Kegiatan saat baca ditemukan kurangnya partisipasi dan kemampuan siswa dalam memahami isi bacaan, sehingga siswa kurang mampu menjawab pertanyaan yang berhubungan dengan bacaan. Siswa juga kurang mampu menemukan ide pokok bacaan sehingga rangkuman yang dihasilkan belum mencakup semua isi bahan bacaan. Kemudian pada kegiatan pascabaca bimbingan guru dalam merangkum isi bahan bacaan juga kurang dilakukan secara maksimal. Hal ini berujung pada sulitnya siswa membuat rangkuman isi bacaan. Dengan demikian, dapat dikatakan bahwa proses pembelajaran membaca belum terlaksana secara efektif dan mencapai hasil yang maksimal.

Pada pelaksanaan kegiatan pembelajaran, ada beberapa kemungkinan strategi yang dapat diterapkan. Namun, berdasarkan paparan dari permasalahan yang telah dikemukakan di atas. Penulis memilih strategiOverview, Key ideas, Read, Record, Recite, Review, Reflect (OK5R) untuk mengembangkan bahan ajar pada pembelajaran tematik terpadu terutama bahasa Indonesia. Strategi Overview, Key ideas, Read, Record, Recite, Review, Reflect (OK5R) menurut (Istarani, 2012:167) merupakan suatu strategi membaca yang dapat membantu siswa untuk menyelidiki, menemukan ide-ide kunci, membaca, mencatat, mendaras, mengulang, dan merenungkan dari isi teks yang dibaca.

Istarani (2012:169) menjelaskan kelebihan dari strategi Overview, Key ideas, Read, Record, Recite, Review, Reflect (OK5R) adalah strategi ini mencakup beragam aktivitas belajar dan mengajar, sehingga materi yang disampaikan dapat diserap ilmunya dengan baik oleh siswa, dapat membantu siswa dalam memahami bacaan secara menyeluruh, karena sambil membaca siswa juga dituntut untuk dapat membuat catatan penting dari bahan bacaan yang telah dibaca, pemahaman siswa terhadap bacaan akan lebih tahan lama karena siswa diminta untuk melakukan perenungan kembali dari teks bacaan tersebut, serta dapat memunculkan daya berfikir kritis dan kreatif siswa .

Tujuan dari penelitian ini adalah (1) menganalisis kebutuhan siswa berkaitan dengan bahan ajar membaca dalam hati. (2) Mengembangkan bahan ajar membaca 
dalam hati pada pembelajaran tematik terpadu dengan strategi OK5R di Kelas IV SD. (3) Menguji validitas bahan ajar yang dihasilkan.

\section{METODE PENELITIAN}

Jenis penelitian ini merupakan penelitian pengembangan yang lebih kita kenal dengan istilah Research and Development $(R \& D)$. Penelitian ini tergolong penelitian pengembangan karena dalam penelitian ini bertujuan untuk menemukan, mengembangkan, dan memvalidasi suatu produk (Kurniawan \& Dewi, 2017). Jenis penelitian ini adalah penelitian pengembangan dengan model pengembangan Plomp yang terdiri dari tiga tahap, yaitu: (1) preliminary research, (2) prototyping phase, dan (3) assesment stage.

Prosedur pengembangan memuat tahap-tahap yang harus dilakukan dalam setiap pengembangan yang akan dilakukan. Prosedur pengembangan ini sesuai dengan tahap-tahap model pengembangan Plomp. Skema rancangan penelitian dilihat pada bagan berikut:

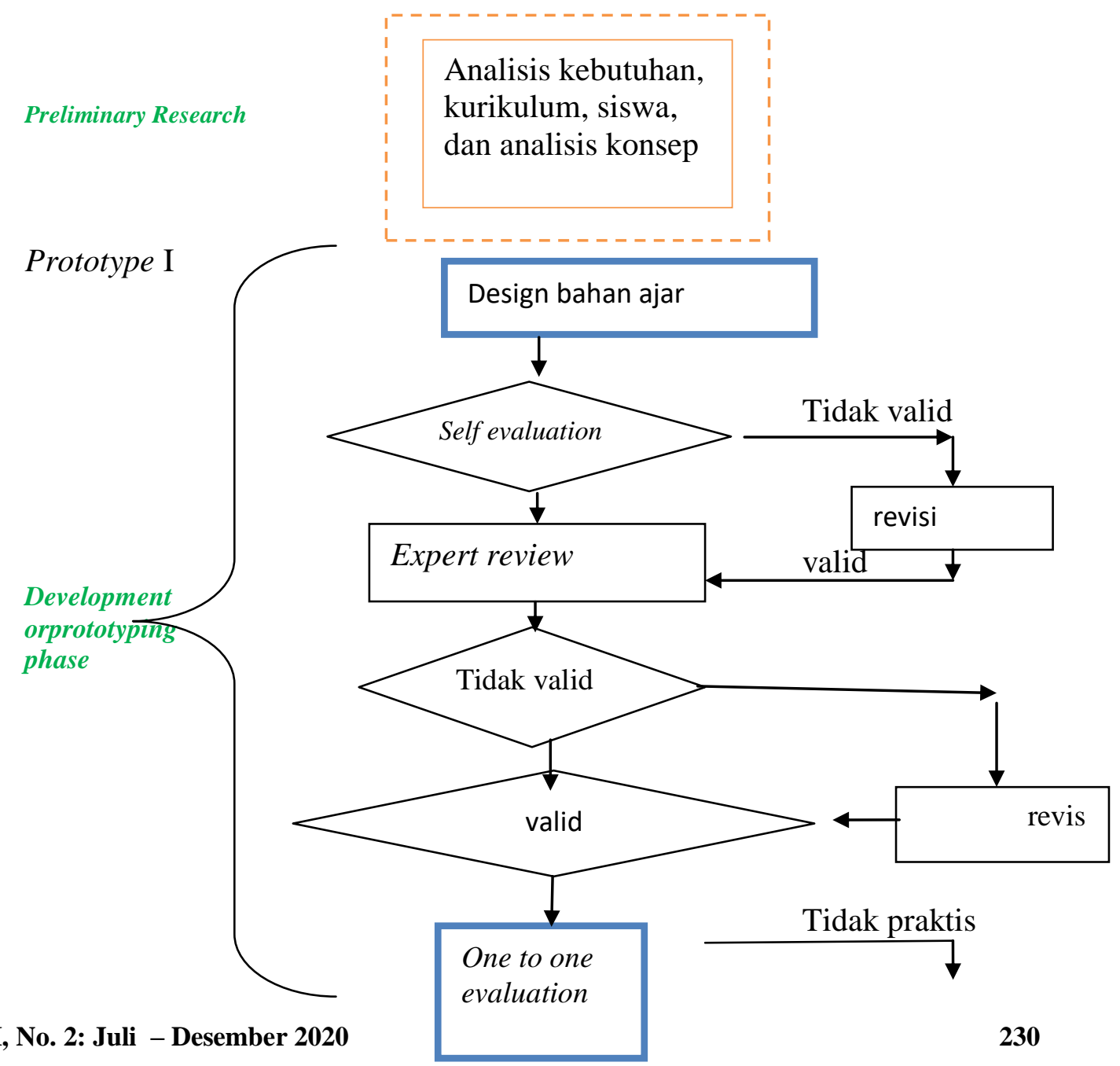

Vol. VI, No. 2: Juli - Desember 2020 


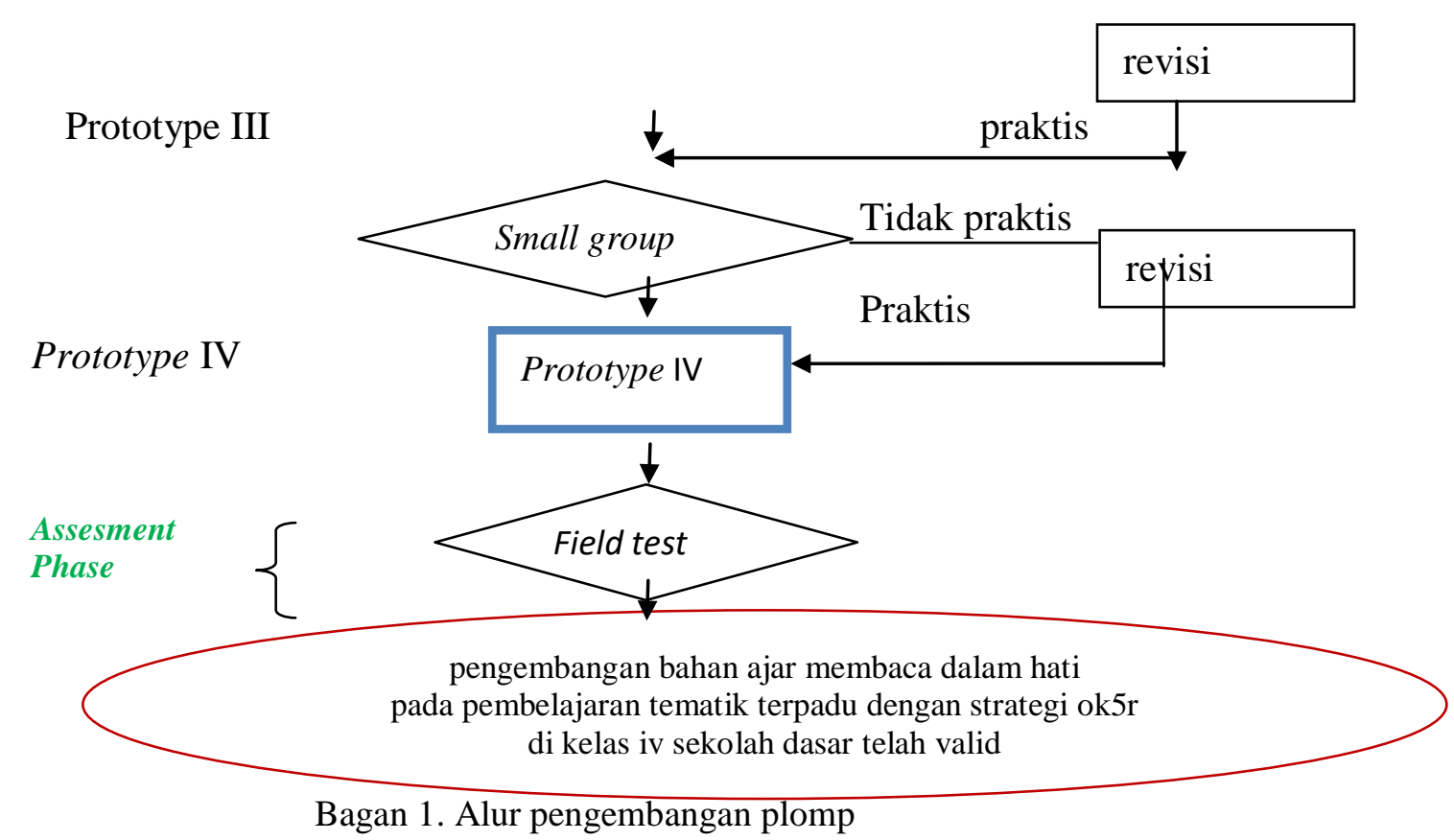

Langkah-langkah bahan ajar di atas dapat dirincikan sebagai berikut:

\section{Analisis Pendahuluan (Preliminary Stage)}

Fase ini dibutuhkan untuk mendapatkan informasi mengenai permasalahan dalam bidang pendidikan (terdapat kesenjangan di antara situasi yang ada dengan yang diharapkan). Fase analisis pendahuluan ini terdapat beberapa tahap yaitu sebagai berikut: (1) Analisis kebutuhan dilakukan untuk mengetahui masalah dasar yang dibutuhkan dalam pengembangan bahan ajar dengan strategi OK5R dengan tujuan agar adanya kesesuaian antara bahan ajar yang digunakan dengan kurikulum. Analisis kebutuhan yang dilakukan salah satunya yaitu menganalisis bahan ajar yang digunakan di Sekolah Dasar. Analisis yang dilakukan melihat dua aspek utama, yaitu isi teks (content) dan tampilan( desain); (2) Analisis Kurikulum , tahap analisis kurikulum ini dilakukan terhadap kurikulum 2013 kelas IV SD semester I pada tema 1 kelas IV. Analisis kurikulum dilakukan dengan menganalisis kompetensi inti, kompetensi dasar, indikator-indikator, cakupan materi, dan tujuan pembelajaran yang harus dicapai. Hasil analisis kurikulum tersebut dianalisis agar bahan ajar yang dihasilkan sesuai dengan tuntutan kompetensi yang harus dicapai oleh siswa; (3) Analisis Karakteristik Siswa, Analisis karakteristik dilakukan untuk mengetahui keadaan siswa di kelas IV SD yang akan menjadi sasaran penggunaan bahan ajar. Dengan menganalisis karakteristik siswa akan memudahkan guru dalam pengembangan bahan ajar. Adapun bahan ajar yang dikembangkan adalah 
berdasarkan karakteristik siswa kelas IV sekolah dasar; (4) Analisis Konsep, Analisis konsep merupakan identifikasi materi-materi yang akan dibahas pada pembelajaran. Materi-materi ini disusun secara sistematis dengan mengaitkan suatu konsep dengan konsep lain yang relevan sehingga membentuk suatu konsep. Selain itu juga dilakukan identifikasi terhadap materi-materi yang sudah dipelajari siswa, tujuannya untuk melihat cakupan materi yang sudah dikuasai oleh siswa agar dalam pelaksanaan penelitian tidak terjadi hambatan-hambatan. Analisis konsep ini bertujuan untuk mengidentifikasi konsep-konsep utama dalam membaca dalam hati di kelas IV SD dan menyusun konsep-konsep secara sistematis sesuai dengan KI, $\mathrm{KD}$, indikator, dan tujuan pembelajaran yang telah dianalisis.

\section{Tahap Perancangan (Prototyping Stage)}

Tahap perancangan yaitu peneliti merancang bahan ajar kemampuan membaca dalam hati sebagai upaya meningkatkan pembelajaran tematik terpadu dengan menggunakan strategi OK5R di kelas IV Sekolah Dasar. Rancangan bahan ajar disesuaikan materi dengan kurikulum 2013, kesesuaian dengan karakteristik siswa yang terdiri dari isi, bahasa dan kegrafikaan serta kesesuaian dengan strategi OK5R yang membutuhkan pemahaman siswa dan merancang RPP sesuai dengan format yang terdapat dalam Permendikbud No. 22 tahun 2016. Tahap perencanaan model pengembangan Plomp terdiri dari:

\section{Evaluasi diri sendiri (self evaluation)}

Evaluasi diri sendiri (self evaluation) yaitu mengevaluasi prototype yang sudah dirancang dan dilakukan oleh peneliti sendiri beserta teman sejawat. Tujuannya untuk mengecek ulang bahan ajar yang telah dibuat agar tidak terjadi kesalahan. Hasil perancangan pada tahap ini menghasilkan prototype I bahan ajar membaca dalam hati sebagai upaya meningkatkan pembelajaran tematik terpadu dengan meningkatkan membaca dalam hati dengan menggunakan strategi OK5R. Setelah hasil evaluasi sendiri kemudian dilakukan revisi. Selanjutnya dilakukan uji validitas terhadap prototype I.

\section{Penilaian Ahli (Expert Review)}

Setelah dihasilkan prototype I, kemudian dilakukan penilaian pakar atau ahli (expert reviews). Penilaian pakar atau ahli yaitu meminta pakar atau ahli untuk memberikan penilaian dan masukan terhadap prototype yang sudah 
dirancang dengan memvalidasi bahan ajar. Penilaian ini dilakukan untuk menemukan kelebihan dan kelemahan dari rancangan yang telah dibuat. Melihat validasi produk yang dihasilkan, maka dilakukan diskusi dengan para pakar untuk mendapatkan masukan-masukan yang dapat memperbaiki bahan ajar.

\section{Tahap Penilaian (Assesment Stage)}

Tahapan ini tidak dilaksanakan karena fokus penelitian hanya sampai validitas bahan ajar saja.

\section{HASIL DAN PEMBAHASAN}

\section{Analisis Pendahuluan (Preliminary Stage)}

Berdasarkan hasil analsiis yang telah dilakukan, ditemukan:

- Kurangnya penerapan teknik membaca dalam hati yang benar di antaranya, membaca dengan tidak bersuara, bibir tidak bergerak atau komat-kamit, tidak menggerakkan kepala mengikuti baris bacaan, tidak menunjuk baris bacaan dengan jari, pensil, atau alat lainnya, dan tidak membaca kata demi kata, atau kalimat demi kalimat. Sehingga menyebabkan tingkat kemampuan membaca siswa menjadi rendah.

- Penerapan membaca belum terlaksana sesuai dengan proses membaca yaitu: prabaca, saat baca, dan pascabaca sehingga kurangnya pemahaman siswa terhadap suatu bacaan.

- Karakteristik pembelajaran tematik kurang terlihat, hal ini disebabkan karena pembelajaran kurang terlihat berpusat kepada siswanya tetapi masih mengarah kepada teacher center, pembelajaran belum memberikan pengalaman secara langsung kepada siswa, pemisahan antar pelajaran masih dirasakan oleh siswa, sehingga proses pembelajaran tematik terpadu menjadi kurang efektifdikarenakan karakteristik pembelajaran tematik belum terlihat.

- Kegiatan pada tahapan pascabaca pada kegiatan menyimpulkan isi bacaan dan mengomunikasikan isi teks bacaan belum terlaksana dengan baik.

- Tidak diterapkannya strategi membaca yang tepat menyebabkan rata-rata siswa hanya mampu membaca secara monoton, menerapkan gaya membaca yang sama untuk setiap bahan bacaan, bahkan lebih buruk lagi siswa tidak pernah tahu bagaimana cara praktis dalam memahami bacaan. 


\section{Tahap Perancangan (Prototyping Stage)}

Adapun rancangan bahan ajar yang dihasilkan adalah sebagai berikut:

Cover

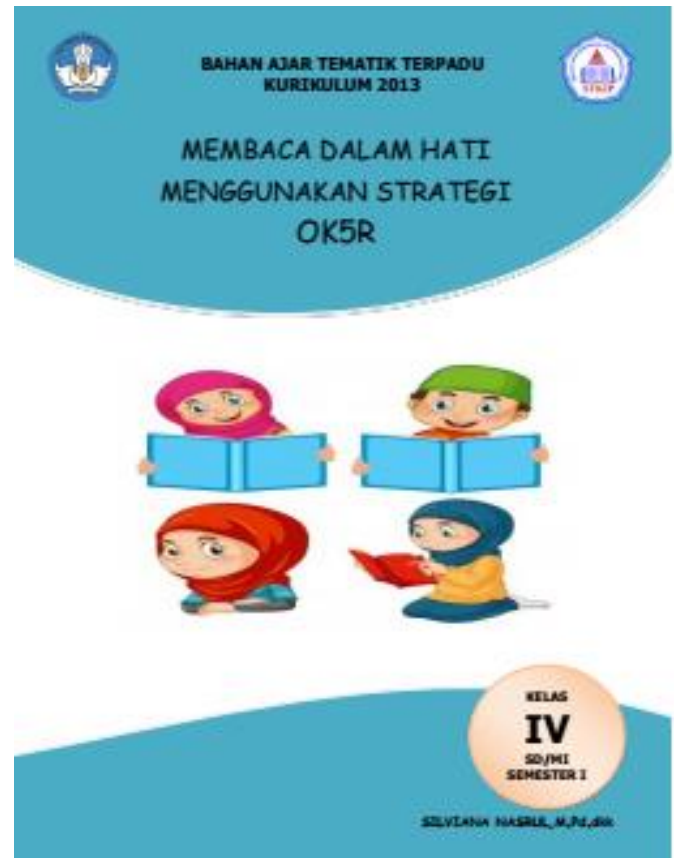

Kata pengantar

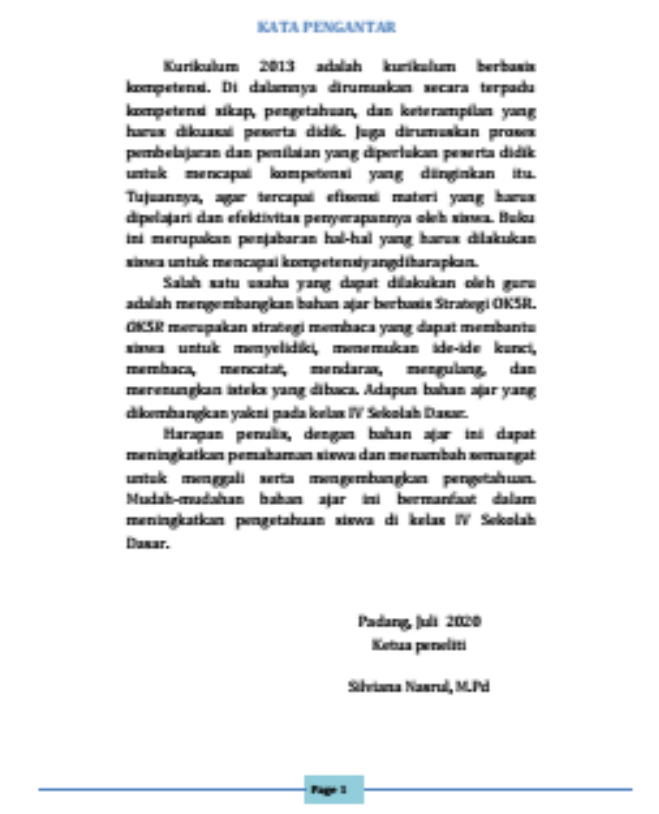

Petunjuk penggunaan 


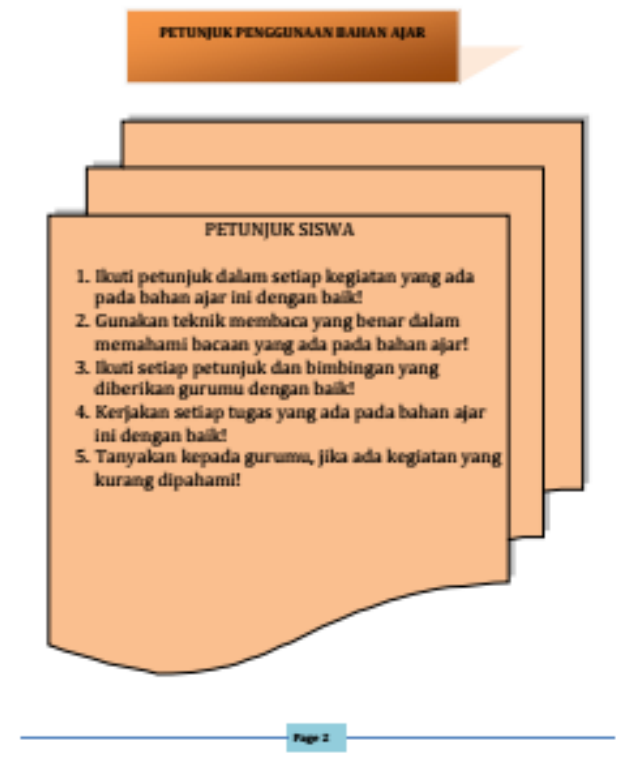

Bagian isi

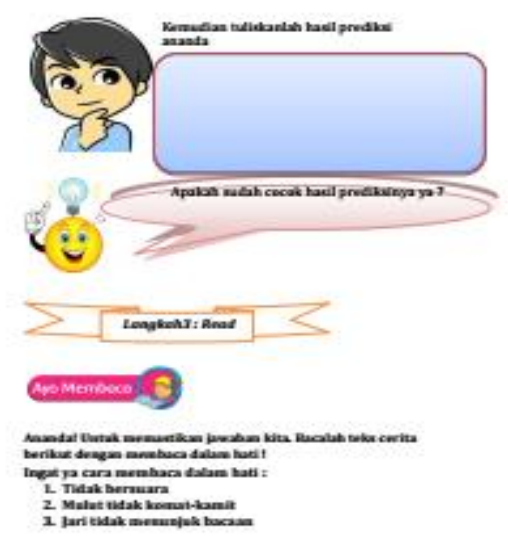

Selanjutnya dilakukan validasi oleh tim ahli

\section{Validitas bahan ajar}

\begin{tabular}{cllcl}
\hline No. & \multicolumn{1}{c}{ Nama Validator } & \multicolumn{1}{c}{ Keahlian } & Hasil & Kriteria \\
\hline 1 & Dr. Jendriadi, M.Pd. & Kebahasaan & $91 \%$ & Sangat valid \\
\hline 2 & Meria Ultra Gusteti, M.Pd. & design & $92 \%$ & Sangat valid \\
\hline 3 & Silfi Melindawati, M.Pd. & Materi & $93 \%$ & Sangat valid \\
\hline
\end{tabular}


Berdasarkan hasil dari validator tersebut dapat disimpulkan bahwa bahan ajar yang peneliti kembangkan sudah valid dengan rata-rata $92 \%$ dengan kritera sangat Valid

\section{Tahap Penilaian (Assesment Stage)}

Tahapan ini tidak dilaksanakan karena fokus penelitian hanya sampai validitas bahan ajar saja.

\section{SIMPULAN}

Berdasarkan hasil penelitian pengembangan abahn ajar yang telah dilakukan, dapat disimpilkan sebagai berikut:

- Berdasarkan analisis kebutuhan, ditemukan bahwa bahan ajar yang digunakan belum menerapkan proses membaca dengan benar, yaitu belum menerapkan prabaca, saatbaca, dan pascabaca, serta pada materi emmbaca dalam hati belum menerapkan proses membaca dalam hati yang tepat.

- ada proses perancangan telah menghasilkan design bahan ajar yang berbasis strategi OK5R.

- $\quad$ Pada uji validitas bahan ajar memperoleh hasil dari 3 validator dengan rata-rata 92\% dengan kriteria sangat valid.

\section{DAFTAR PUSTAKA}

Apfani.S. (2018). Pengembangan bahan ajar membaca berorientasi kooperatif tipe CIRC di kelas IV Sekolah Dasar.Jurnal inovasi pendidikann dan pembelajaran sekolah dasar, 2(1),13-28. https://doi.org/10.24036/jippsd.v2i1.100033

Taufina, F. (2016). Penilaian Pembelajaran Bahasa dan Apresiasi Sastra Indonesia. Bandung: Angkasa Bandung.

Taufina, T., \& Chandra, C. (2018). The Implication of Authentic Assessment in Thematic Integrated Learning Process at Lower Level Elementary School Early Childhood Development. Advances in Social Science, Education and Humanities Research (ASSEHR) International Conference of Early Childhood Education (ICECE 2017), 169(February). https://doi.org/10.2991/icece-17.2018.36 